\title{
QUALIDADE FISIOLÓGICA DE SEMENTES DE FEIJÃO EM PLANTIO DIRETO SOBRE DIFERENTES COBERTURAS DE PLANTAS EM DIAMANTINA, MG
}

\author{
Physiological quality seeds of bean in no-tillage system over different coverings \\ of plants in Diamantina, MG ${ }^{1}$
}

\author{
Ubirajara Russi Nunes ${ }^{1}$, Nelson França Santos ${ }^{3}$, Múcio Magno de Melo Farnezi ${ }^{3}$, \\ Valter Carvalho Andrade Júnior ${ }^{1}$, Delacyr da Silva Brandão Júnior ${ }^{1}$, Geraldo Durães Pereira²
}

\begin{abstract}
RESUMO
Objetivou-se com este trabalho avaliar o efeito de diferentes coberturas de plantas sobre a qualidade fisiológica de sementes de feijão em plantio direto no município de Diamantina - MG. O experimento foi instalado no Campus II da UFVJM, num Neossolo Quartzarênico Órtico típico, no delineamento em blocos casualizados, com dez tratamentos e quatro repetições. Os tratamentos constituíram-se de palhada dessecada e roçada de 1) Brachiaria decumbens cv. Basilisk, 2) Brachiaria brizantha cv. Marandu, 3) Panicum maximum cv. Tanzânia, 4) Panicum maximum cv. Mombaça, 5) Mucuna aterrina (mucuna preta), 6) Calopogonio muconoides cv. Calopogonio, 7) Dolichos lab lab (lab lab), 8) Cajanus cajan (guandu), 9) Cobertura natural e 10) Plantio convencional onde se efetuou o plantio de feijão cultivar Talismã. A qualidade fisiológica das sementes foi avaliada pelos testes de germinação (primeira contagem e contagem final); condutividade elétrica dos solutos; peso de 100 sementes; comprimento e peso das plântulas; índice de velocidade de germinação e teor de água das sementes de feijão. As gramíneas Panicum. maximum cv. Mombaça, Brachiaria brizantha cv. Marandu, B. decumbens cv. Basilisk e P. maximum cv. Tanzânia produziram matéria seca em quantidade e uniformidade para maior conservação de água e proteção do solo para viabilizar o sistema plantio direto. A qualidade das sementes não foi afetada pelos manejos de solo utilizados e sim pelas condições climáticas na maturação.
\end{abstract}

Termos para indexação: Phaseolus, coberturas, germinação.

\section{ABSTRACT}

The objective this work was evaluate the effect of different coverings plants on the physiological quality seeds of bean in notillage system in Diamantina - MG. The experiment was installed in the Campus II of UFVJM, in a Neossolo Quartzarênico Órtico típico, in blocks randomized design, with ten treatments and four replicates. The treatments were constituted of control chemical and rubbed straw of 1) Brachiaria decumbens cv. Basilisk, 2) Brachiaria brizantha cv. Marandu, 3) Panicum maximum cv. Tanzania, 4) Panicum maximum cv. Mombaça, 5) Mucuna aterrina (black mucuna), 6) Calopogonio muconoides cv. Calopogonio, 7) Dolichos lab lab (lab lab), 8) Cajanus cajan (guandu), 9) Natural covering and 10) Conventional plantation where the bean plantation was made to cultivate Talisman. The physiological quality of the seeds was evaluated by the germination tests (first and final count); electric conductivity of the solute; weigh of 100 seeds; length and weight of the plants; index of germination speed and text of water of the bean seeds. The grass Panicum. maximum cv. Mombaça, Brachiaria brizantha cv. Marandu, B. decumbens cv. Basilisk and $P$. maximum cv. Tanzania produced dry matter in amount and uniformity for larger conservation of water and protection of the soil to make possible the no-tillage system. The quality of the seeds was not affected by the used soil handlings but had the influence of the climatic conditions in the maturation.

Index terms: Phaseolus, cover plants, germination.

(Recebido em 29 de agosto de 2005 e aprovado em 20 de julho de 2006)

\section{INTRODUÇÃo}

Na região dos Cerrados ocorrem precipitações pluviais de grande intensidade, flutuações de temperatura e umidade do solo, elevada taxa de decomposição de resíduos orgânicos e lixiviação de nutrientes que intensificam a degradação do solo e contribuem para o processo erosivo e o declínio da produtividade das lavouras.

Sistemas agrícolas viáveis economicamente e que garantem, a longo prazo, a qualidade ambiental e a preservação dos recursos naturais, representam uma

\footnotetext{
'Engenheiro Agrônomo, D.S., Professor Adjunto - Universidade Federal do Vale do Jequitinhonha e Mucuri/UFVJM - $39100-000$ - Diamantina, MG russinunes@yahoo.com.br; valterjr@fafeid.edu.br; delacyr@hotmail.com

²Engenheiro Agrônomo, M.S., EMATER - 39100-000-Diamantina, MG - gdurães@citel1.com.br

${ }^{3}$ Acadêmico do curso de Agronomia - Universidade Federal do Vale do Jequitinhonha e Mucuri/UFVJM - 39100-000 - Diamantina, MG francanelson@bol.com.br; mfarnezi@bol.com.br.
} 
alternativa de produção para a região. Entre as estratégias possíveis de se utilizar destacam-se o controle da erosão, o manejo do solo e de resíduos culturais, a reciclagem de nutrientes e a utilização de plantas de cobertura do solo (ALVARENGA et al., 2001).

O estabelecimento de plantas de cobertura é uma das práticas agrícolas que tem demonstrado eficiência para auxiliar no controle da erosão, via manutenção de resíduos vegetais na superfície do solo. Quando as plantas de cobertura morrem, ocorre a liberação dos nutrientes com a sua decomposição e, enquanto existirem restos de cobertura morta, o solo continua protegido contra os agentes de erosão e perda de água. Durante o período chuvoso, a cobertura do solo promove proteção contra o impacto direto da gota de chuva, impedindo a formação de crosta e reduzindo a formação de enxurrada (ALVARENGA et al., 2001).

O plantio direto é um sistema de manejo do solo que envolve uma série de práticas agrícolas, entre as quais a utilização de plantas de cobertura para formação de palhada alterando, basicamente, as suas propriedades químicas, físicas e biológicas (SIQUEIRA, 1995). Vários trabalhos têm evidenciado mudanças nestes atributos quando submetidos à técnica do plantio direto em comparação ao plantio convencional (ALVARENGA, 1996; MERTEM, 1994; SILVA et al., 1996; SIQUEIRA, 1995).

A maioria dos trabalhos referentes aos componentes de rendimento e a produtividade das culturas relacionadas com a utilização de plantas de cobertura e com o sistema de plantio direto não relatam resultados e pesquisas com informações sobre a qualidade fisiológica das sementes produzidas nestas condições. Desta forma, o presente trabalho foi desenvolvido com o objetivo de avaliar a qualidade fisiológica das sementes de feijão produzidas sobre a palhada de diferentes plantas de coberturas no sistema plantio direto no município de Diamantina-MG.

\section{MATERIAL E MÉTODOS}

O trabalho foi realizado nos anos agrícolas de 2.002 a 2004, no Campus II da Universidade Federal dos Vales do Jequitinhonha e Mucuri (UFVJM), em Diamantina, MG. (18 ${ }^{\circ}$ 'S e 43⒉' $\mathrm{W}$, altitude média de $1296 \mathrm{~m}$, temperatura média anual de $18,1^{\circ} \mathrm{C}$ ). Os dados de precipitação pluviométrica, coletados no período do trabalho e médias entre 1971 a 1990, na Estação Meteorológica de Diamantina (INMET, 2004), estão na Figura 1.

$\mathrm{O}$ experimento foi instalado em um Neossolo Quartzarênico Órtico típico, textura arenosa, cujos resultados da análise química $(0 \mathrm{a} 20 \mathrm{~cm})$ foram: $\mathrm{pH}$ em água 5,6; MO $27 \mathrm{~g} \mathrm{~kg}^{-1} ; 1,0 \mathrm{mg} \mathrm{dm}^{-3} \mathrm{de} \mathrm{P} ; 16 \mathrm{mg} \mathrm{dm}^{-3} \mathrm{de} \mathrm{K}^{+}$;

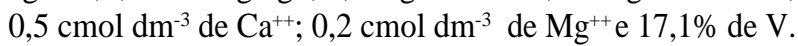

O preparo e a correção do solo foram realizados em 20/02/2002 e consistiram, respectivamente, de uma aração e duas gradagens e aplicação de calcário dolomítico (PRNT $100 \%$ ) na dosagem de $3 \mathrm{t} \mathrm{ha}^{-1}$. Em seguida, foram formadas 33 parcelas de $36 \mathrm{~m}^{2}(6 \times 6 \mathrm{~m})$ aplicando-se, manualmente, a lanço, $250 \mathrm{~kg} \mathrm{ha}^{-1}$ de Superfosfato simples, determinados com base na análise química do solo.

Em cada parcela foram utilizadas as seguintes espécies de cobertura como tratamentos: Brachiaria decumbens Stap $f$ cv. Basilisk; Brachiaria brizantha (Hochst. ex. A. Rich.) Stapf cv. Marandu; Panicum maximum Jacq. cv. Tanzânia; Panicum maximum Jacq. cv. Mombaça; Mucuna aterrima (Piper et Tracy) Holland; Calopogonium mucunoides Desv. cv. Calopogônio; Dolichos lab lab L.; Cajanus cajan (L.) Millsp.; Crotalaria juncea L.; cobertura natural (parcela em pousio) e plantio convencional (parcela testemunha, sempre capinada). Cada espécie foi estabelecida em semeadura convencional entre os dias 11/03/2002 e 15/03/2002, em linha ou a lanço, com densidade de plantas e espaçamento realizado de acordo com a recomendação técnica para cada cultura.

Durante o ano de 2002 e até 21/11/2003 as espécies cresceram livremente nas parcelas, sem o controle de plantas daninhas, visando à obtenção de cobertura vegetal. Realizou-se capina somente nas parcelas testemunha (plantio convencional).

A amostragem das parcelas foi realizada em 03/11/ 2003, utilizando-se, para isso, uma armação em madeira medindo $0,25 \mathrm{~m}^{2}$, a qual foi lançada aleatoriamente em cada parcela. Neste dia, também foi avaliada a porcentagem de cobertura do solo, em cada parcela, em notas atribuídas individualmente para cada espécie. Foi coletada toda a massa verde que se encontrava na área de $0,25 \mathrm{~m}^{2}$ (incluindo plantas daninhas). Após a coleta as amostras foram ensacadas, identificadas e secadas em estufa por 72 horas e $70^{\circ} \mathrm{C}$, obtendo-se o peso da matéria seca.

No dia 21/11/2003, para dessecação das coberturas nas parcelas, foi aplicado o herbicida glifosato na dose de $1,8 \mathrm{~kg} \mathrm{ha}^{-1}$ i.a, com pulverizador costal. No dia 26/11/2003, as coberturas foram roçadas mecanicamente e, em seguida, realizado o plantio direto do feijão, utilizando-se semeadora-adubadora de tração mecânica.

A adubação do feijão (Phaseolis vulgaris L. cv. Talismã) foi de $50 \mathrm{~kg} \mathrm{ha}^{-1}$ de Cloreto de potássio, $400 \mathrm{~kg} \mathrm{ha}^{-1}$ de Superfosfato simples e $250 \mathrm{~kg} \mathrm{ha}^{-1}$ de Sulfato de amônio (40\% da dose aplicada no sulco e $60 \%$ em cobertura, trinta dias após a emergência do feijão). Utilizou-se o espaçamento de $0,50 \mathrm{~m}$ entre linhas e quinze sementes por 


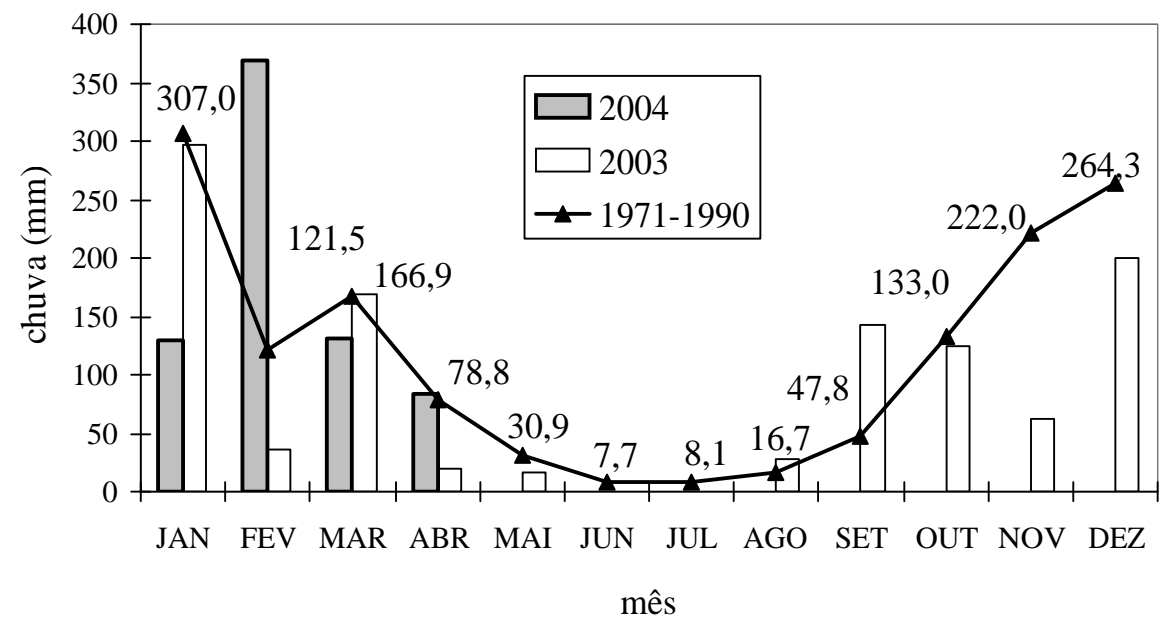

Figura 1 - Distribuição mensal da chuva em Diamantina, MG - 2006.

metro. Seis dias após a emergência procedeu-se o desbaste, obtendo-se dez plantas por metro.

Foram realizadas três capinas nas parcelas com o feijão para o controle das plantas daninhas. Não foram realizados tratamento fúngico ou inoculação de sementes ou tratamentos fitossanitários na cultura.

Em cada parcela, no dia 12/03/2004, no estádio fenológico R8, foram colhidas manualmente amostras de plantas e, em seguida, as sementes foram debulhadas das vagens e secas ao sol, até apresentarem teor de água entre 10 e $11 \%$ (base úmida). Após passarem por processos de limpeza e uniformização quanto ao tamanho, as sementes foram submetidas aos testes para avaliação da qualidade fisiológica: Peso de 100 sementes: Utilizaram-se quatro subamostras de 100 sementes por tratamento, as quais foram pesadas em balança de precisão de 0,01g. Grau de umidade: Foi realizado pelo método da estufa a $105^{\circ} \mathrm{C} \pm 3^{\circ} \mathrm{C}$ por 24 horas (BRASIL, 1992). Germinação das sementes: Realizado com quatro repetições de 50 sementes, semeadas entre três folhas de papel-toalha, umedecidas com água desmineralizada, com peso equivalente a três vezes o peso do papel seco. Foram confeccionados rolos, sendo estes levados para germinador regulado a $25^{\circ} \mathrm{C}$ (BRASIL, 1992). As contagens foram feitas aos cinco e nove dias. Primeira contagem do teste de germinação: Obtida na primeira contagem do teste de germinação. Índice de velocidade de germinação: Foi realizado em conjunto com o teste de germinação, computando-se diariamente o número de sementes germinadas (protusão da radícula primária com $1 \mathrm{~mm}$ ). Condutividade elétrica das soluções: Realizada por meio de quatro repetições de 25 sementes não-danificadas. Cada amostra foi pesada em balança com precisão de $0,01 \mathrm{~g}$ e a seguir imersas em $75 \mathrm{~mL}$ de água desmineralizada no interior de copos plásticos. Os copos foram colocados em incubador a $25^{\circ} \mathrm{C}$, por 24 horas. Ao final deste período, efetuou-se as leituras de condutividade elétrica em condutivímetro Digimed CD-4301. Os resultados obtidos foram divididos pelo peso das amostras, e a condutividade elétrica expressa em $\mu \mathrm{mhos} / \mathrm{cm} / \mathrm{g}$ (VIEIRA, 1994). Comprimento das plântulas: Utilizaram-se quatro subamostras de 20 sementes por tratamento. Os rolos de papel-toalha foram levados para o germinador a $25^{\circ} \mathrm{C}$, durante cinco dias e após determinados os comprimentos das plântulas normais com o auxílio de uma régua graduada em milímetros. Peso da matéria seca das plântulas: Foi avaliado utilizando-se todas as plântulas normais das amostras que foram usadas para determinação do comprimento das plântulas. As amostras foram colocadas em saquinhos de papel e levadas para secar em estufa a $65^{\circ} \mathrm{C}$, por 24 horas, obtendo-se dados médios em g/ plântula.

O delineamento experimental utilizado para avaliação das coberturas e qualidade fisiológicas das sementes de feijão foi o de blocos casualizados, com respectivamente, três e quatro repetições. As médias foram comparadas entre si pelo teste de Tukey a 5\% de probabilidade. Os resultados em porcentagem, para germinação e vigor, foram transformados em arco-seno $\sqrt{\% / 100}$ para análise estatística e as médias apresentadas com os valores originais.

\section{RESULTADOS E DISCUSSÃO}

Houve diferença significativa entre os tratamentos para a variável peso da matéria seca. Os maiores valores 
foram obtidos pelas gramíneas braquiária decumbens, capim colonião cv. Tanzânia, capim colonião cv. Mombaça e b. brizantha, com respectivamente, $11.173,33 \mathrm{~kg} / \mathrm{ha}, 11000$ $\mathrm{kg} / \mathrm{ha}, 6480 \mathrm{~kg} / \mathrm{ha}$ e $6200 \mathrm{~kg} / \mathrm{ha}$ (Tabela 1). Entre os tratamentos com espécies de leguminosas e o tratamento com cobertura natural não houve diferença significativa. $\mathrm{Na}$ época em que foram coletadas as amostras de coberturas (próximo ao plantio de feijão) grande parte da massa vegetal das leguminosas já havia sido decomposta, e estas foram substituídas pela vegetação presente no local do experimento, o que explica o resultado e evidencia a dificuldade de obtenção e a baixa persistência da palhada de espécies de rápida decomposição.

Para as gramíneas, os valores obtidos são essencialmente devido à produção de matéria seca dessas espécies, sem interferência de plantas espontâneas, isto porque foram eficientes na produção e uniformidade de cobertura do solo em relação às demais (Tabela 1). A permanência de maior volume de palha das gramíneas está condicionada à taxa de decomposição do material no campo, ou seja, elas apresentam relação $\mathrm{C} / \mathrm{N}$ e teores de lignina mais amplos, o que pode resultar em lenta mineralização, ou disponibilidade de nutrientes da palhada, com possibilidade de produzir efeitos benéficos a longo prazo. De acordo com Alvarenga et al. (2001), a quantidade de palha sobre o solo e a uniformidade de sua distribuição podem servir de referência para uma avaliação preliminar sobre as condições nas quais o sistema de plantio direto (SPD) está se desenvolvendo. No entanto, apenas as gramíneas superaram os $6000 \mathrm{~kg} /$ ha considerado como a quantidade mínima ideal de palhada para cobertura do solo para o sistema de plantio direto. Segundo Alvarenga et al. (2001), o desafio do SPD na região dos Cerrados, onde imperam condições de clima seco no inverno (Figura 1) e fotoperíodo curto, e alta taxa de decomposição da palhada no início do verão, reside no fato de se obter o estabelecimento de cobertura do solo em março ou abril com quantidade e rusticidade suficiente para que haja fornecimento constante de material ao solo até o início do plantio da cultura subsequente.

Nas Tabelas 2 e 3 são apresentados os resultados da qualidade física e fisiológica das sementes. Os testes discriminaram diferenças significativas na qualidade das sementes produzidas, com exceção da variável grau de umidades das sementes e peso de plântulas.

Para a variável peso de 100 sementes os melhores resultados foram obtidos nos tratamentos capim colonião cv. mombaça, b. brizantha, b. decumbens e capim colonião cv. tanzânia, justamente onde foram obtidos os maiores valores de peso de matéria seca das coberturas (Tabelas 1 e 2).

Oliveira et al. (2002) constataram que o milheto com produção de matéria seca acima de $14000 \mathrm{~kg} / \mathrm{ha}$, propiciou a maior proteção do solo, maior conservação da água e menor variação da temperatura no solo, favorecendo a formação e aumento do peso de grãos. Também ressaltam que o maior acúmulo de macronutrientes, e a relação $\mathrm{C} / \mathrm{N}$ desta espécie possibilitou maior tempo de permanência da palhada na superfície do solo, resultando em maior rendimento de grãos. Entretanto, Nakagawa et al. (2003), analisando o efeito de sistemas de preparo do solo (convencional e direto) na qualidade física e físiológica de sementes de soja produzidas em sucessão a cultivos de crotalária e guandu, verificaram que a massa de 100 sementes foi semelhante para os sistemas de manejo de solo e sucessão.

A capacidade germinativa das sementes foi sensivelmente afetada em todos os tratamentos (Tabela 2). Os tratamentos com as coberturas capim colonião cv. Mombaça e sempre capinado apresentaram maior germinação e índice de velocidade de germinação, mas não diferiram dos tratamentos com as coberturas lab lab, mucuna preta e calopogônio. Porém, em nenhum dos tratamentos foi possível a obtenção de sementes com o padrão mínimo de $80 \%$ de germinação, exigido pela Comissão Estadual de Sementes e Mudas de Minas Gerais (CESM-MG) para comercialização (LOBATO et al., 1985).

Essa situação pode ser vislumbrada analisando o vigor das sementes (Tabela 3). Na primeira contagem observa-se que a perda do vigor foi evidente, com alguns tratamentos indicando perda quase total da viabilidade.

Para o comprimento de plântula houve diferença apenas entre o tratamento sempre capinado, com o maior valor e as coberturas com capim colonião cv. Tanzânia, calopogônio e guandu, com os menores valores dessa característica.

Pelo teste de condutividade elétrica dos solutos constata-se a perda do vigor das sementes. Os valores expressivos de condutividade elétrica encontrados são resultantes do vazamento de eletrólitos das membranas celulares alteradas pelo processo de deterioração. Para esta variável, novamente observa-se a melhor qualidade das sementes produzidas nas coberturas capim colonião cv. Mombaça e tratamento sempre capinado em relação aos demais.

Trabalhando com diferentes coberturas com gramíneas, vegetação espontânea e sem vegetação em semeadura direta, Cavariani et al. (2001) concluíram que a cobertura com gramínea influenciou positivamente no vigor de sementes de soja. Gomes Júnior et al. (2003) estudaram o 
Tabela 1 - Valores médios de peso de matéria seca das coberturas (MS) e cobertura do solo. FAFEID, Diamantina, MG $2005^{1}$.

\begin{tabular}{lcc}
\hline \multicolumn{1}{c}{ Tratamentos } & MS (kg/ha) & Cobertura do solo (\%) \\
\hline Panicum maximum cv. Mombaça & $6.480,00 \mathrm{ab}$ & 80 \\
Brachiaria brizantha cv. Marandu & $6.200,00 \mathrm{ab}$ & 80 \\
Brachiaria decumbens cv. Basilisk & $11.173,33 \mathrm{a}$ & 95 \\
Panicum maximum cv. Tanzânia & $11.000,00 \mathrm{a}$ & 90 \\
Calopogônio muc. cv. Calopogônio & $3.266,66 \mathrm{~b}$ & 40 \\
Cajanus cajan & $4.013,33 \mathrm{~b}$ & 25 \\
Cobertura natural & $4.546,66 \mathrm{~b}$ & 40 \\
Mucuna aterrina & $4.733,33 \mathrm{~b}$ & 40 \\
Dolichos lab lab & $2.960,00 \mathrm{~b}$ & 35 \\
\hline CV (\%) & 28,00 & \\
\hline
\end{tabular}

${ }^{1}$ Os valores seguidos das mesmas letras na vertical não diferem estatisticamente pelo teste de Tukey, a 5\% de probabilidade.

Tabela 2 - Valores médios de grau de umidade (GU), peso de 100 sementes (P100), germinação (G) e índice de velocidade de germinação (IVG) de sementes de feijão, cultivar Talismã, em plantio direto sobre diferentes coberturas de solo. FAFEID, Diamantina, MG - $2005^{1}$.

\begin{tabular}{lllll}
\hline \multicolumn{1}{c}{ Tratamentos } & GU $(\%)$ & P100 & G $(\%)$ & IVG \\
\hline Panicum maximum cv. Mombaça & $10,11 \mathrm{a}$ & $21,72 \mathrm{a}$ & $72 \mathrm{ab}$ & $58,41 \mathrm{ab}$ \\
Brachiaria brizantha cv. Marandu & $10,23 \mathrm{a}$ & $21,75 \mathrm{a}$ & $47 \mathrm{bcd}$ & $37,20 \mathrm{cde}$ \\
Brachiaria decumbens cv. Basilisk & $10,28 \mathrm{a}$ & $20,72 \mathrm{ab}$ & $40 \mathrm{cde}$ & $32,04 \mathrm{def}$ \\
Panicum maximum cv. Tanzânia & $10,55 \mathrm{a}$ & $21,42 \mathrm{ab}$ & $19 \mathrm{e}$ & $12,62 \mathrm{f}$ \\
Calopogônio muc. cv. Calopogônio & $10,43 \mathrm{a}$ & $19,72 \mathrm{bc}$ & $63 \mathrm{abcd}$ & $52,37 \mathrm{abcd}$ \\
Cajanus cajan & $10,34 \mathrm{a}$ & $19,47 \mathrm{c}$ & $38 \mathrm{de}$ & $30,35 \mathrm{ef}$ \\
Cobertura natural & $10,39 \mathrm{a}$ & $19,48 \mathrm{c}$ & $49 \mathrm{bcd}$ & $40,91 \mathrm{bcde}$ \\
Sempre capinado & $10,46 \mathrm{a}$ & $19,37 \mathrm{c}$ & $77 \mathrm{a}$ & $63,81 \mathrm{a}$ \\
Mucuna aterrina & $10,59 \mathrm{a}$ & $19,62 \mathrm{bc}$ & $62 \mathrm{abcd}$ & $45,25 \mathrm{abcde}$ \\
Dolichos lab lab & $10,26 \mathrm{a}$ & $19,62 \mathrm{bc}$ & $65 \mathrm{abc}$ & $53,22 \mathrm{abc}$ \\
\hline CV $(\%)$ & 2,30 & 3,70 & 20,16 & 20,39 \\
\hline
\end{tabular}

${ }^{1}$ Os valores seguidos das mesmas letras na vertical não diferem estatisticamente pelo teste de Tukey, a 5\% de probabilidade.

efeito de doses de nitrogênio e sistemas de cultivo na qualidade fisiológica de sementes de feijão e constataram que no cultivo convencional ocorreu baixa porcentagem de sementes enrugadas e manchadas e maiores valores para vigor, germinação e índice de velocidade de germinação em comparação ao plantio direto.

Durante todo o ciclo de desenvolvimento do feijão, no presente trabalho, ocorreram $890 \mathrm{~mm}$ de chuva (Figura 1) e é possível que as coberturas tenham propiciado, por um lado, maior proteção do solo, menor evaporação e, portanto, aumento na capacidade de armazenamento de água da chuva. Entretanto, como houve grande volume de água no período, a palhada (principalmente nas coberturas brachiaria decumbens e capim colonião cv. Tanzânia) também pode ter funcionado como barreira física para a liberação do excesso de água, mantendo a superfície do solo sempre úmida. Essa situação permaneceu até a fase de maturação do feijão, sendo a umidade em excesso 
Tabela 3 - Valores médios de vigor (V), comprimento de plântulas (CP), peso de plântulas (PP) e condutividade elétrica dos solutos (CE) de sementes de feijão, cultivar Talismã, em plantio direto sobre diferentes coberturas de solo. FAFEID, Diamantina, $\mathrm{MG}-2005^{1}$.

\begin{tabular}{lcccc}
\hline \multicolumn{1}{c}{ Tratamentos } & $\mathrm{V}(\%)$ & $\mathrm{CP}(\mathrm{cm})$ & $\mathrm{PP}(\mathrm{g})$ & $\mathrm{CE}(\mu \mathrm{mhos} / \mathrm{cm} / \mathrm{g})$ \\
\hline Panicum maximum cv. Mombaça & $55 \mathrm{a}$ & $19,05 \mathrm{ab}$ & $0,16 \mathrm{a}$ & $96,68 \mathrm{~d}$ \\
Brachiaria brizantha cv. Marandu & $26 \mathrm{bcd}$ & $17,27 \mathrm{ab}$ & $0,16 \mathrm{a}$ & $212,81 \mathrm{ab}$ \\
Brachiaria decumbens cv. Basilisk & $17 \mathrm{~cd}$ & $17,63 \mathrm{ab}$ & $0,16 \mathrm{a}$ & $179,09 \mathrm{bc}$ \\
Panicum maximum cv. Tanzânia & $2 \mathrm{~d}$ & $15,78 \mathrm{~b}$ & $0,15 \mathrm{a}$ & $250,22 \mathrm{a}$ \\
Calopogônio muc. cv. Calopogônio & $37 \mathrm{abc}$ & $16,06 \mathrm{~b}$ & $0,15 \mathrm{a}$ & $194,00 \mathrm{bc}$ \\
Cajanus cajan & $17 \mathrm{~cd}$ & $15,24 \mathrm{~b}$ & $0,15 \mathrm{a}$ & $196,64 \mathrm{abc}$ \\
Cobertura natural & $24 \mathrm{bcd}$ & $18,81 \mathrm{ab}$ & $0,16 \mathrm{a}$ & $165,00 \mathrm{bc}$ \\
Sempre capinado & $61 \mathrm{a}$ & $21,89 \mathrm{a}$ & $0,16 \mathrm{a}$ & $97,36 \mathrm{~d}$ \\
Mucuna aterrina & $47 \mathrm{ab}$ & $18,76 \mathrm{ab}$ & $0,16 \mathrm{a}$ & $197,55 \mathrm{abc}$ \\
Dolichos lab lab & $57 \mathrm{a}$ & $19,01 \mathrm{ab}$ & $0,16 \mathrm{a}$ & $151,14 \mathrm{c}$ \\
\hline CV $(\%)$ & 32,81 & 11,34 & 2,00 & 12,65
\end{tabular}

${ }^{1}$ Os valores seguidos das mesmas letras na vertical não diferem estatisticamente pelo teste de Tukey, a 5\% de probabilidade.

prejudicial à qualidade das sementes. Tolentino Júnior \& Scheeren (2003), avaliando a influência da chuva na maturação que antes e depois da chuva a germinação foi de 96 e $24,5 \%$ e o vigor foi de 73 e $37,5 \%$, respectivamente. Dessa forma, concluíram que a incidência de chuvas após a maturação fisiológica das sementes na região dos Cerrados afeta negativamente a qualidade, comprometendo sua utilização como semente. Nakagawa et al. (2003) afirmam que os sistemas de preparo de solos e as sucessões estudadas não ocasionaram modificações na qualidade fisiológica das sementes de soja sendo atribuído às condições climáticas (chuva) na fase final de maturação de grãos a não obtenção de sementes de boa qualidade. Na parcela sempre capinada o excesso de água, principalmente na fase de maturação das sementes, pode ter sido drenada ou escorrida superficialmente, diminuindo a umidade superficial, o que pode explicar a melhor qualidade das sementes neste tratamento em relação aos demais.

\section{CONCLUSÕES}

A utilização de leguminosas plantadas isoladamente, antes do período de escassez de chuvas, não é indicada para produção de matéria seca para o sistema plantio direto.

As gramíneas produzem matéria seca em quantidade e uniformidade para maior conservação de água e proteção do solo para viabilizar o sistema plantio direto.

A qualidade fisiológica das sementes de feijão é afetada pelas condições climáticas na maturação em detrimento aos manejos de solos utilizados.

\section{AGRADECIMENTOS}

À Fundação de Amparo à Pesquisa do Estado de Minas Gerais (FAPEMIG), pela concessão de bolsa de iniciação científica.

\section{REFERÊNCIAS BIBLIOGRÁFICAS}

ALVARENGA, A. P. Resposta da planta e do solo ao plantio direto e convencional, de sorgo e feijão, em sucessão a milho, soja e crotalária. 1996. 162 f. Tese (Doutorado em Solos e Nutrição de Plantas) - Universidade Federal de Viçosa, Viçosa, 1996.

ALVARENGA, R. C.; CABEZAS, W. A. L.; CRUZ, J. C.; SANTANA, D. P. Plantas de cobertura de solo para sistema plantio direto. Informe Agropecuário, Belo Horizonte, v. 22, n. 208, p. 25-36, jan./fev. 2001.

BRASIL. Ministério da Agricultura, do Abastecimento e da Reforma Agrária. Secretaria Nacional de Defesa Agropecuária. Regras para Análise de Sementes. Brasília, DF, 1992. 365 p. 
CAVARIANI, C.; LIMA, E. V.; CRUSCIOL, C. A. C.; NAKAGAWA, J. Qualidade fisiológica de sementes de soja em função da cobertura vegetal e da calagem superficial na implantação do sistema de semeadura direta. In: CONGRESSO BRASILEIRO DE SEMENTES, 12., 2001, Curitiba.Informativo ABRATES, Londrina, v. 11, n. 2, p. 90, 2001.

GOMES JÚNIOR, F. G.; LIMA, E. R.; SÁ, M. E. de; SILVA, A. M.; SÁ, A. A. B. de. Qualidade de sementes de feijão em função de doses de nitrogênio em cobertura em dois sistemas de cultivo. In: CONGRESSO BRASILEIRO DE SEMENTES, 13., 2003, Gramado. Informativo ABRATES, Londrina, v. 13, n. 3, p. 286, 2003.

INSTITUTO NACIONAL DE METEOROLOGIA. INMET Belo Horizonte, 2004. Disponível em: <http:// www.inmet.gov.br>. Acesso em: 20 abr. 2004.

LOBATO, L. C.; SELMA, M.; CARVALHO, J. R. M.; CARVALHO, V. M. Normas, padrões e procedimentos para produção de sementes básicas, certificadas e fiscalizadas. 2. ed. Belo Horizonte: Secretaria da Agricultura - MG, 1985. $116 \mathrm{p}$.

MERTEM, G. H. Rendimentos de grãos de feijão em diferentes sistemas de preparo do solo com tração animal. In: REUNIÃO BRASILEIRA DE MANEJO E CONSERVAÇÃO DO SOLO E DA ÁGUA, 10., 1994, Florianópolis. Resumos... Florianópolis: SBSC, 1994. p. 178-179.

NAKAGAWA, J.; GASPAR, C. M.; SANTOS, J. R.; CARDOSO, C. L.; BICUDO, S. J. Qualidade de sementes de trigo e de soja em função de sistemas de preparo de solo e da sucessão de culturas. Acta Scientiarum: Agronomy, Maringá, v. 25, n. 1, p. 73-80, 2003.

OLIVEIRA, T. K. de; CARVALHO, G. J. de; MORAES, R. N. S. Plantas de cobertura e seus efeitos sobre o feijoeiro em plantio direto. Pesquisa Agropecuária Brasileira, Brasília, v. 37, n. 8, p. 1079-1087, ago. 2002.

SILVA, V. A. da; ANDRADE, M. J. B. de; RAMALHO, M. A. P. Efeitos de métodos de preparo do solo e níveis de fertilizante NPK sobre o feijão da "seca" (Phaseolus vulgaris $\mathrm{L}$.) em seqüência à cultura do milho. In: REUNIÃO NACIONAL DE PESQUISA DE FEIJÃO, 5., 1996, Goiânia. Anais... Goiânia: Embrapa-CNPAF, 1996. v. 1, p. 418-420. (Documentos, 69).

SIQUEIRA, N. S. Influência de sistemas de preparo sobre algumas propriedades químicas e físicas do solo e sobre a cultura do milho (Zea mays L.). 1995. 78 f. Tese (Doutorado em Solos e Nutrição de plantas) - Universidade Federal de Viçosa, Viçosa, 1995.

TOLENTINO JÚNIOR, C. F.; SCHEEREN, B. R. Influência da chuva na qualidade fisiológica de sementes de soja “cultivar Jatobá". In: CONGRESSO BRASILEIRO DE SEMENTES, 13., 2003, Gramado. Informativo ABRATES, Londrina, v. 13, n. 3, p. 128, 2003.

VIEIRA, R. D. Teste de condutividade elétrica. In: VIEIRA, R. D.; CARVALHO, N. M. Testes de vigor em sementes. Jaboticabal: FUNEP, 1994. 164 p. 